\title{
Feedback Provision in Mentoring Conversation - Differing Mentor and Student Perceptions
}

\author{
Bettina Korver ${ }^{1} \&$ Harm Tillema $^{2}$ \\ ${ }^{1}$ University of Leiden, The Netherlands. E-mail: bettinakorver@me.com \\ ${ }^{2}$ University of Johannesburg South Africa, South Africa \\ Correspondence: Harm Tillema, University of Johannesburg South Africa, Department of Educational Psychology, APK \\ Campus, B421, Johannesburg, South Africa
}

\author{
Received: November 23, 2013 Accepted: December 10, 2013 Online Published: November xx, 201x \\ doi:10.11114/jets.v2i2.289 \\ URL: http://dx.doi.org/10.11114/jets.v2i2.289
}

\begin{abstract}
Diverging perceptions between a mentor and a mentee on the nature and content of feedback given in mentoring conversations may have a profound impact on the mentee's learning from conversation. This study gauges whether approaches to mentoring relate to establishing congruency in perceptions on provided feedback. The aim of this research is to study differences in mentor and student perceptions of feedback provided during mentoring sessions. For that purpose, this study compares typical mentoring approaches across different settings.

Sixty eight students (37 Teaching Assistant (TA) students in secondary vocational education and 31 Teacher Education (TE) students in Higher Education) and their mentors participated in this study. Mentoring conversations on teaching internships of these students were analyzed. A questionnaire instrument was used to gauge 1) acceptance of feedback from mentoring as well as 2) following recommendations after feedback provision. Approaches to mentors' conversation styles were identified with an observation instrument categorizing mentoring into four types. TA students predominantly recognized their mentor's approach as having a Imperator (supervising) style, while the TE students identified it as an Initiator (engaging style). As a result, TA students expressed a higher degree of acceptance of feedback, as compared to TE students. Differences in perception between students and their mentors on feedback provision were found to be significant.
\end{abstract}

Our findings point to the importance of mentoring approach as it impinges on the feedback acceptance in mentoring conversations.

Keywords: Feedback provision, mentoring conversation, mentor styles, teacher education

\section{Introduction}

In mentoring, feedback provision is a process of fundamental importance (Wiliam, 2011). Providing and using feedback, however, are strongly dependent on the way both the deliverer and the receiver of feedback perceive the mentoring conversation (Mena Marcos \& Tillema, 2006). This study intends to uncover the alignment in feedback (mis)perceptions between mentors and their students, in relation to the differing mentoring approaches used in conversation. We expect that congruency, i.e., shared mentoring goals, adds to the utility of feedback (Shute, 2008).

The process of providing feedback meant to enhance a student's achievement (Hattie, 2009) can be viewed as a two staged, reciprocal activity of: on the one hand monitoring or focus on "assessment for learning" (Wiliam, 2011) which deals with evaluating the students' learning process, which, on part of the student, requires acceptance of evaluative information; and on the other hand, scaffolding as a process of guiding and enhancing further learning by giving advice and suggestions for planned action that, on part of the student, may lead to following recommendations (See PatEl, Tillema, Segers \& Vedder, 2012 for a more detailed account of this twofold process). The reciprocity of assessment/evaluation and enhancement/guidance is typical for mentoring (Tillema \& van der Westhuizen, 2013); and, in a mentoring conversation, occurs within a high frequency of interexchange (Boshuizen, Bromme and Gruber, 2004, pp. 164-166). During conversation, both mentor and student search for understanding and confirmation with regard to interpreting past performance and are "meaning making" on attainments of the student, for the purpose of amendments and identification of further needs of the student (Dochy, Heylen \& Van de Mosselaar, 2002, p. 22; Black \& Wiliam, 
1998). The process underneath an effective feedback provision (Sadler, 1989) may include the following key features: (1) diagnosis of current state; (2) evaluation of progress made relative to standards set; (3) providing informative feedback that motivates the students to accept the assessment; (4) giving advice on how to follow recommendations for the acquisition of required skills and knowledge (James \& Fleming, 2004; Hattie \& Timperley, 2007).

The impact these features have on student's learning from feedback depends highly on the way they are communicated during conversation (Shute, 2008). Brinko (1993) captured this concisely into four W-questions (and an H-question) to characterize the feedback process in mentoring: What (the information that is fed back), When (the occasion upon which the information is fed back), Where (the location in which the information is fed back is psychologically safe), and How (the manner in which the information is given and received). These ' $\mathrm{W} / \mathrm{H}$ ' questions, however, can be very differently interpreted by stakeholders. Carless (2006) explored possible different interpretations of students and their mentors with regard to feedback giving and noted how divergent viewpoints in goals and plans act as barriers to distort the acceptance of feedback and its subsequent following of recommendations. In order for an alignment in perceptions to occur Carless conceived giving and interpreting feedback in mentoring as consisting of three interlocking components: (1) Discourse: the way feedback is communicated must be fully understood; (2) Power: the (often) authoritative position of the feedback giver, i.e., mentor, must help to facilitate acceptance of feedback; and (3) Willingness: the mentee as recipient of feedback must be personally involved and willing to invest time and effort in following recommendations.

Our contention then is: As conversation is the major vehicle of exchange between a mentor and a mentee, it may be highly vulnerable to misinterpretation, since different perceptions may arise on what to accept and how to follow recommendations. How then, i.e., by what mentoring approaches, are mentoring conversations being conducted to reinforce the mentee's acceptance and following recommendations, and make feedback work.

\subsection{Mentoring Approaches in Conversation}

Mentoring can be a highly powerful learning environment to promote learning because of its close and direct interaction between one who "teaches" and one who "learns" (Garvey, Stokes \& Megginson, 2009). Delivering feedback during a mentoring session builds on tailored comments to the learner, in close connection to the student's zone of proximal development. Characteristic of a mentoring relationship (Clutterbuck \& Megginson, 2009) is mutuality in: honesty, openness, sensitivity, self-awareness, and reflexivity, which supports student's learning and motivates. Feedback should, therefore, be provided with clarity of intents (to accept advice), feasibility of comments made (to follow recommendations), and trust in the relationship (to have a conversation) (Tillema, 2009).

The complexity of effective feedback provision in a mentoring relationship lies, among other things, in the intricate alignment of perceptions regarding a) what to attain; b) what has been achieved, and c) how far one has progressed from a to $\mathrm{b}$ (Sadler, 2010). Feedback provision in a mentoring relationship can be looked upon as a double-edged sword, with on one hand the mentor acting as a scaffold, while at the same time keeping evaluative standards high. A mentor may then select different strategies or approaches to cope with this duality. Following Tillema \& Kremer-Hayon (2005) there are three dilemmas or strategic choices to be made in selecting a mentoring approach in conversation: (1) Reflection versus Action, that is, offering space for experiencing or questioning to stimulate reflection as opposed to promoting planned action and resolve; (2) Supervising versus Facilitating, i.e., talking together in or as a community of learners, as opposed to advice giving under scrutiny of performance; (3) Delivery or Inquiry, i.e., giving support by using a telling-method, or by waiting to discover, accepting students' initiatives, thus dealing with students differently (Garvey et al., 2009). Resolving these dilemmas results in different mentoring approaches that can be recognized in conversations (Crasborn, Hennissen, Brouwer, Korthagen \& Bergen, 2011). Tillema \& Smith (2007) identified following approaches: (1) Instructive/prescriptive approach, as giving directions, with its prime focus on progress made, evaluated against targets being set, (2) Relational approach, which rests highly on self regulated learning and input given by the student, (3) Situational approach, in which the mentor acts as a (performance) coach to stimulate learning, using articulation of shared goals. These mentoring approaches in conversation may highly influence the student's acceptance and use of given feedback. This study then particularly looks at differences in mentoring approaches and how it affects perceptions of feedback provision by the mentee. We conjecture that ways in which conversations are conducted by the mentor will result in different outcomes when it comes to acceptance of advice and its subsequent following of recommendations by the mentee. For this purpose we studied mentoring conversations on student teacher learning as a setting for this study and compared different mentoring approaches in a performance oriented teacher education program versus a reflective oriented program teacher education program.

The main research question of this study is: to what extent do feedback perceptions of mentees relate to mentoring approach of mentors. 


\section{Method}

This study was conducted within the internships courses of two teacher education programs. The total sample was comprised of four third-year groups of student teachers, two at the level of secondary vocational education (TA - teacher assistant program) and two at the level of professional higher education (TE - teacher education program) in The Netherlands. The programs differed in two important ways when mentoring is concerned: in the TA program mentors have individual sessions with their students to assess the degree to which a set of pre-specified competences are attained/completed during the internship period (both assessed formatively/process based as well as summative/outcome based), whereas the TE mentors appraise their students internship activities formatively during group sessions and provide reflective support (formatively), while external assessors/supervisors assess the attainment levels separately and in a summative way. The mentoring quality in the TA is dependent on explicit coverage of predefined appraisal criteria, i.e., "protocolized"; in the TE setting highly dependent on conversational and relational skills of the mentor.

A total of 68 students participated together with their mentor: 37 Teaching Assistant students ( 26 female, 11 male) with age ranging from 19 to 22, and 31 Teacher Education students ( 31 female, 1 male) with age ranging from 20 to 24 . The four group related mentors ( 2 female, 2 male) with age ranging from 44 to 50 ( $\mathrm{Sd} 2.5$ ) had working experience as a mentor of 2 to 6 years (mean 4.67, Sd 2.3).

\subsection{Instruments}

This study used a survey questionnaire design. Questionnaire instruments were administered after the internship program by the corresponding mentor to their students. The questionnaires contained both pre-specified instruments as well as a number of open questions. All questionnaire items were measured on Likert scales ranging from 1 to 5 ( $1=$ strongly disagree, and 5 strongly agree), to measure students' appraisal of feedback provision (dependent variables: acceptance of feedback and following recommendations) ) and as well as assessment orientation of mentor and mentee (as presage variable). Mentor approach in conversation was used as a moderator variable.

\subsubsection{Assessment Orientation Questionnaire}

The assessment orientation questionnaire measures student and mentor orientation towards assessment and evaluation of learning. It consists of a Teacher and Student Assessment for Learning Questionnaire version, i.e., the TAFL-Q and SAFL-Q. Explorative and multivariate factor analyses of the instruments were performed by Pat-El, Tillema, Segers \& Vedder (2012) resulting in a stable solution of two factors. Both instruments determine perceptions with regard to a) feedback provision as evaluation and b) support from feedback for further action. The TAFL-Q questionnaire consists of 28 items divided into two scales: (1) Assessment as an aid to Monitor performance; and (2) Assessment as a Scaffold for further learning. In the corresponding SAFL-Q for students 28 items are divided into two scales: (1) Receiving Feedback; and (2) Using Feedback. Receiving Feedback measures the students' perception of feedback acceptance from their mentor whereas Using Feedback measures the students' intent to follow recommendation. Reliability of the scales in this study is high: alpha .92 and .80 respectively (corresponding to the reliabilities found by Pat-El et al., 2012).

\subsubsection{Appraisal of Feedback Instrument}

A questionnaire instrument was constructed to appraise the nature of feedback provision after mentoring conversation to the student having 29 questions. The instrument previously developed and used in a study by Tillema \& Smith, (2006; reliability alpha .87), measures three criteria with respect to the way a mentor conducts a mentoring conversation. The instrument gauges a) clarity (degree of problem understanding gained from conversation by the mentee), b) feasibility of feedback provided comments made by the mentor, and c) trust, degree of trust and confidence in the relationship with the mentor. The Clarity scale ( 9 items) measures the overall rating of the feedback given (with respect to communication and goals to be attained), i.e., "The feedback I receive is clear....". The Trust scale (10 items) refers to the degree of relatedness. i.e., "I rely on the advice of my mentor..."; and the Feasibility scale (10 items) refers to the do-ability of expressed advice to comply to the recommendations given, i.e., "The goals don't discourage me, because I know I can reach them...". Reliability of the scales is: Clarity .85, Trust .87, and Feasibility .82.

\subsubsection{Mentoring Approach Questionnaire}

Mentoring approach in conversation was measured with a questionnaire originally developed by Crasborn, Hennissen, Brouwer, Korthagen, \& Bergen (2011) and modified for the purpose of this study to adapt to the setting of mentoring in teacher education for primary education. The questionnaire contained 24 questions, identical for mentor and students, having four scales corresponding to four types of mentor approaches identified in the study by Crasborn et al.: (1) Initiator; (2) Imperator; (3) Encourager; and (4) Advisor. Initiator refers to the use of non-directive skills and an active, stimulating, implicit way of advice giving. Imperator refers to use of a high degree of directive and active, prescriptive advice giving. Encourager refers to use of non-directive questions and passiveness in discussing topics, and 
Advisor refers to the use of directive skills, combined with passive suggestions for further actions.

\subsubsection{Open Questions}

The student questionnaire booklet also contained a number of open questions asking about student motivation, gauging interest to become a teacher, as well as intentions to finish the program. These questions were meant to give a background perspective on the students' opinions on learning from advice giving and their prospects for further learning. It could provide a figure ground contrast for the questionnaire data. Furthermore some descriptive control variables were measured with regard to student background: birth year, gender, nation of origin, prior completion of the teacher education program.

\subsection{Procedure}

To make sure that students' perception regarding mentoring conversation was measured and not the concerns (and fears) for actual assessment of their performance, the dates of the questionnaire administration were set at the end of the school year, yet after the actual final performance assessment of the students had taken place.

The participating student groups (TE and TA) had been approached previously by the researcher to obtain consent for participation. Students and their corresponding mentors were asked to complete the questionnaires after a short introduction by the main researcher. Respondents were assured about anonymity.

\subsection{Data Analysis}

Homogeneity and reliabilities of questionnaire scales was tested. Results are given in Table 1.

Table 1. Reliability of student questionnaires, with examples of items, number of items, and Cronbach's Alpha

\begin{tabular}{|c|c|c|c|}
\hline Scale & Examples of items & $\begin{array}{l}\text { No.of } \\
\text { items }\end{array}$ & $\begin{array}{l}\text { Cronbach's } \\
\text { Alpha }\end{array}$ \\
\hline $\begin{array}{l}\text { SAFL-Q } \\
\text { Receiving } \\
\text { feedback }\end{array}$ & $\begin{array}{l}\text { My mentor encourages me to look back on my learning process and to think about } \\
\text { what I can do differently next time. }\end{array}$ & 16 & .918 \\
\hline $\begin{array}{l}\text { SAFL-Q } \\
\text { Using Feedback }\end{array}$ & I know which points I need to work on to improve my results. & 12 & .803 \\
\hline \multicolumn{4}{|l|}{ Mentor appraisal } \\
\hline Clarity & The feedback I receive from my mentor is clear. & 9 & .853 \\
\hline Trust & $\begin{array}{l}\text { I rely on the instructions and advice of my mentor, because for me they indicate the } \\
\text { right course. }\end{array}$ & 10 & .872 \\
\hline Feasibility & $\begin{array}{l}\text { The goals, as mentioned by my mentor don't discourage me, because I know I can } \\
\text { reach them. }\end{array}$ & 10 & .817 \\
\hline Mentoring & & & \\
\hline $\begin{array}{l}\text { approach } \\
\text { Initiator }\end{array}$ & $\begin{array}{l}\text { During the feedback session my mentor asks me to reflect on my actions, so I come to } \\
\text { insights by myself. }\end{array}$ & 5 & .592 \\
\hline Imperator & $\begin{array}{l}\text { My mentor asks me, with regard to the assignment, how I think I will perform the } \\
\text { task. }\end{array}$ & 6 & .845 \\
\hline Encourager & My mentor steers me in no way through instructions or advice. & 6 & .702 \\
\hline Advisor & $\begin{array}{l}\text { During the feedback session I mostly come with the topics discussed and my mentor } \\
\text { responds strongly by steering guidance and advice regarding my development. }\end{array}$ & 6 & .769 \\
\hline
\end{tabular}

Differences in perception of feedback and mentoring approach between student groups, and between students and their mentor were analyzed with independent two-tailed t-tests. A Factorial design using multivariate analysis of variance was used to scrutinize group differences in Trust, Clarity, Feasibility. Discrepancy scores (z-scores using the mentor's mean score) were calculated between the mentor and their students with regard to mentoring approach in feedback use.

\section{Results}

Descriptive findings on collected data (means and standards deviations) are presented in Table 2. 
Table 2. Table of means and $\mathrm{Sd}$ for TA $(\mathrm{N}=37)$ and TE $(\mathrm{N}=31)$ on measured variables

\begin{tabular}{llccc}
\hline & \multicolumn{2}{l}{ Mean } & \multicolumn{2}{l}{ Sd } \\
Scale & TA & TE & TA & TE \\
\hline Receiving & 3.49 & 3.17 & .72 & .75 \\
Feedback & & & & \\
Using & 3.71 & 3.52 & .53 & .56 \\
Feedback & & & & \\
\hline Mentor & & & & \\
appraisal & & & & \\
Clarity & 3.64 & 3.34 & .67 & .62 \\
Trust & 3.65 & 3.33 & .71 & .76 \\
Feasibility & 3.47 & 3.34 & .58 & .68 \\
\hline Mentor & & & & \\
approach & & & & \\
Initiator & 3.58 & 3.30 & .67 & .54 \\
Imperator & 3.67 & 2.97 & .81 & .69 \\
Encourager & 2.41 & 2.73 & .77 & .64 \\
Advisor & 3.50 & 2.85 & .67 & .57 \\
\hline
\end{tabular}

Correlations between data collection instruments are presented in Table 3 . Table 2 indicates that TA students rated high on mentor approach: Imperator, and mentor appraisal Trust, Clarity, as well as Feedback acceptance, compared to their TE counterparts. Pearson correlation coefficients show moderate significant (at $\mathrm{p}<.01$ ) associations between variables, with an exception on variable Encourager, which correlates significantly negatively $(\mathrm{p}<.01)$ with all other variables.

Table 3. Correlation variables

\begin{tabular}{|c|c|c|c|c|c|c|c|c|c|c|c|c|}
\hline & & Rec FB & Using $\mathrm{FB}$ & FB Acc & Foll Rec & Clarity & Trust & Feasibility & Initiator & Encourager & Imperator & Advisox \\
\hline Rec FB & $\begin{array}{l}\text { MBO } \\
\text { HEO }\end{array}$ & $\begin{array}{l}1 \\
1\end{array}$ & & & & & & & & & & \\
\hline Using FB & $\begin{array}{l}\text { MBO } \\
\text { HBO }\end{array}$ & $\begin{array}{l}.742^{4 *} \\
.7914 *\end{array}$ & $\begin{array}{l}1 \\
1\end{array}$ & & & & & & & & & \\
\hline FB Acc & $\begin{array}{l}\text { MBO } \\
\text { HBO }\end{array}$ & $\begin{array}{l}.741^{4 *} \\
.661^{* 4}\end{array}$ & $\begin{array}{l}.758^{4 *} \\
.621^{4 *}\end{array}$ & $\begin{array}{l}1 \\
1\end{array}$ & & & & & & & & \\
\hline Foll Rex & $\begin{array}{l}\text { MBO } \\
\text { HBO }\end{array}$ & $\begin{array}{l}.572^{4 *} \\
.694^{4 *}\end{array}$ & $\begin{array}{l}.690^{44} \\
.652^{4 *}\end{array}$ & $\begin{array}{l}.840^{44} \\
.929^{44}\end{array}$ & $\begin{array}{l}1 \\
1\end{array}$ & & & & & & & \\
\hline Clarity & $\begin{array}{l}\text { MBO } \\
\text { HBO }\end{array}$ & $\begin{array}{l}.702^{44} \\
.678^{44}\end{array}$ & $\begin{array}{l}.790^{44} \\
.702^{44}\end{array}$ & $\begin{array}{l}937^{44} \\
.897^{44}\end{array}$ & $\begin{array}{l}.909^{44} \\
.901^{4 *}\end{array}$ & $\begin{array}{l}1 \\
1\end{array}$ & & & & & & \\
\hline Trust & $\begin{array}{l}\text { MBO } \\
\text { HBO }\end{array}$ & $\begin{array}{l}.542^{*} \\
.673^{4 *}\end{array}$ & $\begin{array}{l}.634^{44} \\
.590^{44}\end{array}$ & $\begin{array}{l}.877^{44} \\
.931^{44}\end{array}$ & $\begin{array}{l}.942^{44} \\
.954^{4 *}\end{array}$ & $\begin{array}{l}.858^{44} \\
.794^{44}\end{array}$ & $\begin{array}{l}1 \\
1\end{array}$ & & & & & \\
\hline Feasibility & $\begin{array}{l}\text { MBO } \\
\text { HEO }\end{array}$ & $\begin{array}{l}.687^{44} \\
.615^{4 *}\end{array}$ & $\begin{array}{l}.673^{4 *} \\
.580^{*}\end{array}$ & $\begin{array}{l}.884^{4 *} \\
964^{4 *}\end{array}$ & $\begin{array}{l}.894^{4 *} \\
.941^{4 *}\end{array}$ & $\begin{array}{l}.871^{4 *} \\
.855^{4 *}\end{array}$ & $\begin{array}{l}.822^{4 *} \\
.908^{4 *}\end{array}$ & $\begin{array}{l}1 \\
1\end{array}$ & & & & \\
\hline Intiator & $\begin{array}{l}\text { MBO } \\
\text { HBO }\end{array}$ & $\begin{array}{l}.469^{4} \\
.316\end{array}$ & $\begin{array}{l}.533^{*} \\
.468^{*}\end{array}$ & $\begin{array}{l}.642^{44} \\
.578^{4}\end{array}$ & $\begin{array}{l}.628^{44} \\
.553^{*}\end{array}$ & $\begin{array}{l}.656^{44} \\
.638^{44}\end{array}$ & $\begin{array}{l}.607^{44} \\
.462^{4}\end{array}$ & $\begin{array}{l}.656^{44} \\
.578^{4}\end{array}$ & $\begin{array}{l}1 \\
1\end{array}$ & & & \\
\hline Encourager & $\begin{array}{l}\text { IMBO } \\
\text { HBO }\end{array}$ & $\begin{array}{l}-.555^{44} \\
-.559^{*}\end{array}$ & $\begin{array}{l}-.533^{* 4} \\
-.474^{*}\end{array}$ & $\begin{array}{l}-.818^{44} \\
-.739^{44}\end{array}$ & $\begin{array}{l}-.747^{4 *} \\
-.765^{4 *}\end{array}$ & $\begin{array}{l}-.820^{44} \\
-.613^{44}\end{array}$ & $\begin{array}{l}-.747^{4 *} \\
-.806^{4 *}\end{array}$ & $\begin{array}{l}-.720^{44} \\
-.732^{44}\end{array}$ & $\begin{array}{l}-.654^{4 *} \\
-.521^{*}\end{array}$ & $\begin{array}{l}1 \\
1\end{array}$ & & \\
\hline Imperator & $\begin{array}{l}\text { MBO } \\
\text { HBO }\end{array}$ & $\begin{array}{l}.721^{4 *} \\
.671^{4 *}\end{array}$ & $\begin{array}{l}.734^{44} \\
.5222^{*}\end{array}$ & $\begin{array}{l}.775^{44} \\
.788^{44}\end{array}$ & $\begin{array}{l}.701^{4 *} \\
.715^{4 *}\end{array}$ & $\begin{array}{l}.817^{4 *} \\
.743^{4 *}\end{array}$ & $\begin{array}{l}.647^{4 *} \\
.713^{4 *}\end{array}$ & $\begin{array}{l}.7399^{4 *} \\
.708^{44}\end{array}$ & $\begin{array}{l}.766^{44} \\
501^{*}\end{array}$ & $\begin{array}{l}-.779^{44} \\
-.611^{44}\end{array}$ & $\begin{array}{l}1 \\
1\end{array}$ & \\
\hline Advisor & $\begin{array}{l}\text { MBO } \\
\text { HBO }\end{array}$ & $\begin{array}{l}.555^{44} \\
.635^{44}\end{array}$ & $\begin{array}{l}.640^{44} \\
.528^{*}\end{array}$ & $\begin{array}{l}.776^{44} \\
.844^{44}\end{array}$ & $\begin{array}{l}.739^{44} \\
.787^{4 *}\end{array}$ & $\begin{array}{l}.762^{44} \\
.728^{44}\end{array}$ & $\begin{array}{l}.761^{4 *} \\
.796^{4 *}\end{array}$ & $\begin{array}{l}.727^{4 *} \\
.838^{4 *}\end{array}$ & $\begin{array}{l}.602^{44} \\
578^{*}\end{array}$ & $\begin{array}{l}-.746^{44} \\
-.622^{44}\end{array}$ & $\begin{array}{l}.743^{44} \\
.738^{44}\end{array}$ & $\begin{array}{l}1 \\
1\end{array}$ \\
\hline
\end{tabular}

* Pearson two-tailed significance at $p<001$

$*$ Pearson two-tailed significance at $p<01$

\subsection{Feedback and Mentoring Approach}

A main research expectation concerned the relation between mentor approach and feedback provision. A significant difference was found between TA and TE students on their acceptance of feedback, having a medium effect size $($ Cohen's $d=0.62)$ with $(\mathrm{t}(66)=2.29, \mathrm{p}<.05)$. However, no significant differences between groups TA and TE were 
found on following recommendations. Furthermore, a significant difference between TA and TE students was found for their appreciation of the Imperator mentoring approach, having a large effect size (Cohen's $d=1.29)$, with $(t(66)=3.78$, $\mathrm{p}<.001)$. This was also the case for the mentoring approach Advisor $(\mathrm{t}(66)=4.25, \mathrm{p}<.001)($ Cohen's $d=1.17)$. In this case the TA students expressed a higher appreciation for Advisor approach than TE students.

The variance in appreciation of a mentoring approach was used to analyze each of the four mentor groups in more detail using the discrepancy between the mentor's favored approach against the student's appreciation of the practiced approach as a predicator of feedback acceptance and following recommendations. Table 4 gives the mean discrepancies for each of the four mentored groups.

Table 4. Frequency table of mean differences in perception of feedback with regard to mentoring approach between mentor and mentee within four mentoring groups

\begin{tabular}{|c|c|c|c|c|}
\hline Scale & $\begin{array}{l}\text { Discrepancy Means } \\
\text { Within } \\
\text { Imperator approach } \\
\text { TA group1 }\end{array}$ & $\begin{array}{l}\text { Discrepancy Means } \\
\text { Within } \\
\text { Imperator approach } \\
\text { TA group } 2\end{array}$ & $\begin{array}{l}\text { Discrepancy Means } \\
\text { Within } \\
\text { Initiator approach } \\
\text { TE group } 3\end{array}$ & $\begin{array}{l}\text { Discrepancy Means } \\
\text { Within } \\
\text { Initiator approach } \\
\text { TE group } 4\end{array}$ \\
\hline Receiving Feedback & $.55^{*}$ & .17 & $1.02 * *$ & $.72 * *$ \\
\hline Using Feedback & $.40 *$ & .08 & .37 & .33 \\
\hline $\begin{array}{l}\text { Acceptance } \\
\text { Following } \\
\text { Recommendations }\end{array}$ & $\begin{array}{l}.52^{*} \\
.45^{*}\end{array}$ & $\begin{array}{l}-.33 \\
-.09\end{array}$ & $\begin{array}{l}.25 \\
.29\end{array}$ & $\begin{array}{l}.08 \\
.75^{* *}\end{array}$ \\
\hline $\begin{array}{l}\text { Clarity } \\
\text { Trust } \\
\text { Feasibility }\end{array}$ & $\begin{array}{l}.38 \\
.56 * \\
.58 *\end{array}$ & $\begin{array}{l}-.33 \\
-.05 \\
-.31\end{array}$ & $\begin{array}{l}.41 * \\
.80 * * \\
-.38\end{array}$ & $\begin{array}{l}.51 * \\
.36 \\
.38\end{array}$ \\
\hline $\begin{array}{l}\text { Initiator } \\
\text { Imperator } \\
\text { Encourager } \\
\text { Advisor }\end{array}$ & $\begin{array}{l}-.13 \\
-.20 \\
.89 * * \\
.19\end{array}$ & $\begin{array}{l}-.63 * * \\
.04 \\
.96 * * \\
-.03\end{array}$ & $\begin{array}{l}-.04 \\
.43^{*} \\
.43^{*} \\
.47^{*}\end{array}$ & $\begin{array}{l}-.52 * \\
1.17 * * \\
.61 * * \\
.79 * *\end{array}$ \\
\hline
\end{tabular}

(* $\geq .4$ points difference; $* * \geq .6$ points difference)

The mentor's approach in Group 1 (TA) was analyzed using the student questionnaire on mentor appraisal, which indicated an outspoken Encourager style by the mentor, i.e., using non-directive questions and passiveness in discussing topics. The results on student questionnaire data on feedback provision resulted in significant discrepancies on all feedback related dependent variables. This indicates that the mentor perceived high outcomes on part of the students, more than his students indicated on feedback receiving and use. However in Group 2 (TA) also having an Imperator approach no mean $\mathrm{z}$-score discrepancies were found. It needs to be noted in this case that students acknowledged also an Initiator mentoring approach in conversation (i.e., mentor asking open questions). Group 3 (TE) was found having a mentoring approach characterized by a blend of styles. This mentoring approach showed hardly any discrepancies in perceptions on feedback between students and their mentor. Remarkable in this case are the strong differing perceptions regarding receiving feedback and trust, meaning that the mentor held a more favorable view on these matters than his students. Group 4 (TE), also characterized by students by a blend of mentoring approaches, and demonstrated a difference on mainly receiving feedback and following recommendations and to a lesser degree clarity of recommendations. Apparently, the mentor regards himself as more directive and active than his students.

Overall Table 4 shows that most differences occur with regard to receiving feedback, following recommendations, and clarity of advice. In general, our data indicated that mentors tend to overrate their effort in the feedback process (higher mean scores), while the students' present clearly lower scores on received feedback.

Belonging to either a TA or TE Student group (Table 5) was not significantly related to mentoring approach Initiator, however, it was on Encourager $(F(1,62)=6.160, p<.05, .090)$, Imperator $(F(1,62)=20.187, p<.001, .246)$, and Advisor $(\mathrm{F}(1,62)=20.016, \mathrm{p}<.001, .244)$. 
Table 5. Differences in Mentoring approach perceptions between TA and TE students

\begin{tabular}{lccc}
\hline Scale & $\mathrm{F}$ & $\mathrm{p}$ & $\eta^{2}$ \\
\hline Initiator & 3.583 & .063 & .055 \\
Imperator & 20.187 & .000 & .246 \\
Encourager & 6.160 & .016 & .090 \\
Advisor & 20.016 & .000 & .244 \\
\hline
\end{tabular}

\subsection{Feedback Acceptance and Use}

To further scrutinize possible differences between mentor groups with regard to measured variables, the TA and TE groups were studied in more detail. They differed significantly $(\mathrm{p}<.01)$ both on acceptance and use of feedback. Two interaction effects were noted, on receiving feedback $(\mathrm{F}(1,62)=9.070, \mathrm{p}<.01, .128)$, and on using feedback $(\mathrm{F}(1,62)=$ $6.029, \mathrm{p}<.05, .089$ ). The students' motivation to learn (measured as a background variable) was found to be significantly related $(\mathrm{p}<.05)$ to acceptance and use of feedback. Student motivation had a significant correlation $(\mathrm{p}<.05)$ with trust, clarity, and feasibility. Regression analysis was then utilized to test the influence of each mentored group on variables: Trust, Clarity, and Feasibility of Feedback provision. For TA students a predictive value $\left(\mathrm{R}^{2}\right)$ was found of 0.632 , indicating $63.2 \%$ was explained by appraisal of mentor conversation. Clarity was the strongest predictor $(\beta=.942, \mathrm{t}(33)=3.773, \mathrm{p}<.01)$. Trust and Feasibility showed no significant impact on Using Feedback.

For the TE students Trust, Clarity, and Feasibility accounted for $50.8 \%$ of explained variance. Clarity again is, the strongest predictor of the three predictor variables $(\beta=.744, \mathrm{t}(27)=2.851, \mathrm{p}<.01)$. Again, Trust and Feasibility shows no significant impact.

Looking at our research expectation on variation in mentor approach, we found for the TA students that mentoring approach accounts for $58.3 \%$ of explained variance. Imperator is a significant predictor of Using Feedback $(\beta=.532$, $\mathrm{t}(32)=2.322, \mathrm{p}<.05)$. The mentoring approach Initiator, Advisor, and Encourager did not significantly show impact on Using Feedback, while Initiator and Encourager showed a non-significant negative contribution.

For the TE students mentoring approach accounted for $35.8 \%$ of explained variance. However, none of the mentoring approaches are significantly related to Using Feedback.

\section{Conclusion and Discussion}

This study meant to explore how mentoring approaches used in conversations affects acceptance of feedback and how a mentor's way of providing feedback differentially influences its usage with respect to following recommendations. We contended that student perceptions of the mentor (appraisal) and alignment between mentor and mentee in preference of a mentoring approach would enhance the utilization of feedback.

First it was analyzed whether differences in perceptions on feedback provision were related to mentoring approach (across two settings), and if possible differences were related to appraisal of mentoring approach.

The dominant mentoring approach in both the TA and TE setting was of an Imperator (prescriptive/directive) and Initiator (non-directive/stimulating) style. Our students perceive the Encourager (non-directive/passive) approach to be absent in the feedback they receive. A significant discrepancy (however, small) was found between mentors and their students in their perception of the actual mentoring approach used. Of interest is the large difference found in perception with regard to the mentoring approach Encourager: while mentors meant to deploy this approach, their students perceived this otherwise. Furthermore, a substantial difference between TA and TE setting was found with regard to acceptance of feedback, with TA (having a performance oriented program) expressing a higher mean degree of acceptance of feedback. And again we found that students and mentors differed in their perception of feedback use; while mentors overrated its use, their students were more negative. Especially perceptions regarding receiving feedback, trust, and following recommendations were overrated by the mentors.

Secondly we analyzed whether differences in appreciation of the mentoring conversation, i.e., with regard to Feedback, Trust, Clarity, Feasibility, were related to mentoring approach.

Difference in appreciation of mentoring with regard to setting as well as students' motivation (measured as background variable) had a significant interactive effect on mentoring approaches Imperator and Initiator. While the TE students (i.e., reflective oriented program) expressed a low degree of appreciation for the Imperator approach they favored a high degree of the Initiator approach. In contrast, the TA students (i.e., performance oriented program), irrespective of students' motivation, showed no major difference in preference for either an Imperator or Initiator approach. We also found that students' motivation to learn was of substantial influence on, in particular, the TE student's appraisal of conversation. Apparently these students favor receiving feedback as non-directive and stimulating. In particular, TE student motivation was highly related to all three variables on feedback provision in mentoring conversations: trust, clarity, and feasibility. TE students having negative motivation showed low scores on receiving feedback; and also low 
scores on following recommendations. Apparently, students' motivation to learn has a great impact on feedback utilization (Dweck, 1986).

Thirdly we analyzed whether Feedback provision in conversation: with Trust, Clarity, Feasibility was related to mentoring approach, and if it varied between settings.

Clarity of conversation, in both settings, is the most important factor in utilization of feedback, with its stronger effect showing for the TA setting. Hattie (2009) points out the importance of clarity, meaning to explicate what is meant, how it is conveyed and when it is to deliver during mentoring conversations. Both the TA as the TE students indicated that the mentoring approach Imperator has the most positive effect on clarity of conversation.

With regard to the TA students we found that the mentoring approach Imperator has a significant effect on actual utilization of feedback, while the Initiator and Encourager approach, both being non-directive, contribute in a negative way to utilization of feedback. With regard to the TE students none of the identified mentoring approaches were significant indicators of feedback utilization. The TE students valued the Initiator mentoring approach as most dominant during mentoring sessions, with its low directedness and high stimulation.

For both students groups we found that the Advisor mentoring approach has a positive effect on trust, while the Encourager approach has a negative effect on trust. The TE students expressed this effect in a much stronger way than the TA students. Furthermore, we found that the approach Encourager has a negative effect on clarity. This holds for the TA students in the same way as for the TE students. Also, the TE students indicated that the Advisor approach has a positive influence on feasibility, while the Encourager approach is regarded as more negative with regard to feasibility of following recommendations.

The outcomes of this study raise some questions about the nature of feedback provision in mentoring conversations. We found that students perceive the nature of feedback provision, as well as the mentoring approach being used, in a different way as their mentors do; which causes some concern. The finding was present irrespective of teacher education setting/program, but with some notable differences. TA students perceive their mentors as highly directive in their mentoring approach, while their mentors think they're not; and the TE students perceive mentoring approach of their mentors as low in directiveness. The TE mentors however recognize themselves in another type of mentoring. The question then can be raised how differing perceptions between mentors and their mentees work out on feedback utilization, i.e., does, for instance, a mentor's openness or non-directedness during mentoring conversation result in experiencing a corresponding willingness to accept and follow up of recommendations?, or does a non-alignment negatively influence feedback utilization?

Our findings give some indication on the direction of this mechanism. We assume that importance of alignment in perceptions between mentor and mentees as it relates to feedback use varies with mentoring approach. With regard to the mentoring approach Imperator we found, for instance, that it significantly influenced utilization of feedback for TA students, while the approaches Initiator and Encourager, both being strongly non-directive, contributed in a negative way to use of feedback; while this was not the case for the TE students. This implies that the TA students, more than TE students profit from active, directive feedback input during their mentoring sessions, combined with clear and concrete advice on how to proceed. They indicate that the Imperator mentoring approach is what they would like more (than their mentors), and close alignment would prove to work well for their motivation to learn and utilization of received feedback. In support of this case, we found that the TA students also expressed a higher degree of accepting feedback, as compared to the TE students. However, a question still can be raised whether these findings indicate that feedback under alignment of mentoring approach leads to higher degrees of feedback acceptance.

Also, as previously noted, it needs to be noted that actual perceptions of mentors and their mentees regarding feedback provision showed discrepancy, i.e., with mentors overrating the impact of their feedback provision. Especially trust seems to be overrated by mentors. To narrow a gap in perceptions and have a better grip on how the feedback is perceived, conversational input by the mentee to the mentor could definitely add to an effective feedback process.

Overall this study pointed out some issues of concern regarding the provision of feedback in mentoring conversations. Differences between mentor approaches and (non-)alignment in perceptions between students and their mentors have been highlighted, as well as some factors, both in conducting a conversation as well as in style and approach, that may contribute to a more effective utilization of feedback. One of our main conclusions is, that the clarity of conversation makes the difference. Also setting characteristics (i.e., orientation of mentoring) highly influenced mentoring approaches being used with its impact on the outcomes of feedback. Of relevance in this study is the impact differing perceptions have on effective mentoring.

\section{References}

Black, P., \& Wiliam, D. (1998). Inside the Black Box: Raising standards through classroom assessment. London: School of Education, King's College. 
Boshuizen, H. P. A., Bromme, R., \& Gruber, H. (2004). Professional Learning: Gaps and Transitions on the Way from Novice to Expert. Innovation and Change in Professional Education. Dordrecht: Kluwer Academic Publishers. http://dx.doi.org/10.1007/1-4020-2094-5

Brinko, K. T. (1993). The practice of Giving Feedback to Improve Teaching. Journal of Higher Education, 64(5), 574-592. http://dx.doi.org/10.2307/2959994

Carless, D. (2006). Differing perceptions in the feedback process. Studies in Higher Education, 31(3), $219-233$. http://dx.doi.org/10.1080/03075070600572132

Clutterbuck, D., \& Megginson, D. (2009). Further techniques for coaching and mentoring. Butterworth-Heinemann.

Crasborn, F., Hennissen, P., Brouwer, N., Korthagen, F., \& Bergen, T. (2011). Exploring a two-dimensional model of mentor teacher roles. Teaching and Teacher Education, 27, 320-331. http://dx.doi.org/10.1016/j.tate.2010.08.014

Dochy, F., Heylen, L., \& Van de Mosselaar, H. (2002). Assessment in onderwijs. Utrecht, Lemma.

Dweck, C.S. (1986). Motivational processes affecting learning. American Psychologist, 41, 1040-9. http://dx.doi.org/10.1037/0003-066X.41.10.1040

Garvey, R., Stokes, P., \& Megginson, D. (2009). Coaching and Mentoring: Theory and Practice. London: Sage Publications Ltd.

Hattie, J. (2009). Visible learning: a synthesis of over 800 meta-analyses relating to achievement. New York: Routledge.

Hattie, J., \& Timperley, H. (2007). The Power of Feedback. Review of Educational Research, 77(1), 81-112. http://dx.doi.org/10.3102/003465430298487

James, D., \& Fleming, S. (2004). Agreement in Student Performance in Assessment. Learning and Teaching in Higher Education, 1(05), 32-50.

Mena Marcos, J. J., \& Tillema, H. (2006). Studying studies on teacher reflection and action: An appraisal of research contributions. Educational Research Review, 1, 112-132. http://dx.doi.org/10.1016/j.edurev.2006.08.003

Pat-El, R. J., Tillema, H. H., Segers, M., \& Vedder, P. (2013). Validation of assessment for learning questionnaires for teachers and students. The British Journal of Educational Psychology, 83, 98-113. http://dx.doi.org/10.1111/j.2044-8279.2011.02057.x

Sadler, D. R. (1989). Formative Assessment and the design of instructional systems. Instructional science, 18(2), 119-144. http://dx.doi.org/10.1007/BF00117714

Sadler, D. R. (2010). Beyond feedback: developing student capability in complex appraisal. Assessment \& Evaluation in Higher Education, 35(5), 535-550. http://dx.doi.org/10.1080/02602930903541015

Shute, V. J. (2008). Focus on Formative Feedback. Review of educational research, 78(1), 153-189. http://dx.doi.org/10.3102/0034654307313795

Tillema, H. (2009). Assessment in Learning to Teach. Appraisal of Practice Teaching Lessons by Mentors, Supervisors, and Student Teachers. Journal of Teacher Education, 60(2), 155-167. http://dx.doi.org/10.1177/0022487108330551

Tillema, H., \& Kremer-Hayon, L. (2005). Facing dillemas: teacher-educators' ways of constructing a pedagogy of teacher education. Teaching in Higher Education, 10(2), 203-217. http://dx.doi.org/10.1080/1356251042000337954

Tillema, H., \& K. Smith. (2006). Portfolios for professional development: A research journey. New York: Nova Science Publishers.

Tillema, H., \& Smith, K. (2007). Portfolio appraisal: In search of criteria. Teaching and Teacher Education, 23, $442-456$. http://dx.doi.org/10.1016/j.tate.2006.12.005

Tillema, H., \& Van der Westhuizen, G. (2013) Mentoring conversations and student teacher learning. South African Journal of Higher Education, 27(5), 1305-1323.

Wiliam, D. (2011). 'What is assessment for learning?' Studies in Educational Evaluation, 37(1), 3-14. http://dx.doi.org/10.1016/j.stueduc.2011.03.001

\section{$(\mathrm{cc}) \mathrm{BY}$}

This work is licensed under a Creative Commons Attribution 3.0 License. 